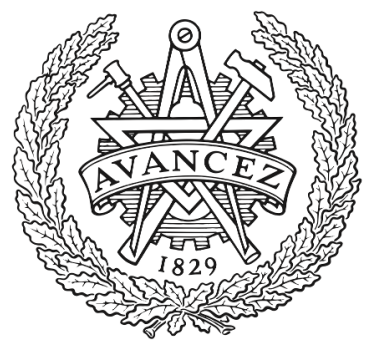

CHALMERS

UNIVERSITY OF TECHNOLOGY

\title{
Investigation of the Influence of Tyre Geometry on the Aerodynamics of Passenger Cars
}

Downloaded from: https://research.chalmers.se, 2023-04-26 12:59 UTC

Citation for the original published paper (version of record):

Hobeika, T., Sebben, S., Landström, C. (2013). Investigation of the Influence of Tyre Geometry on the Aerodynamics of Passenger Cars. SAE International Journal of Passenger Cars - Mechanical Systems, 6(1): 316-325. http://dx.doi.org/10.4271/2013-01-0955

N.B. When citing this work, cite the original published paper. 


\title{
Investigation of the Influence of Tyre Geometry on the Aerodynamics of Passenger Cars
}

\author{
Author, co-author (Do NOT enter this information. It will be pulled from participant tab \\ in MyTechZone) \\ Affiliation (Do NOT enter this information. It will be pulled from participant tab in MyTechZone)
}

Copyright $@ 2012$ SAE International

\begin{abstract}
It is well known that wheels are responsible for a significant amount of the total aerodynamic drag of passenger vehicles. Tyres, and mostly rims, have been the subject of research in the automotive industry for the past years, but their effect and interaction with each other and with the car exterior is still not completely understood. This paper focuses on the use of CFD to study the effects of tyre geometry (tyre profile and tyre tread) on road vehicle aerodynamics. Whenever possible, results of the numerical computations are compared with experiments.
\end{abstract}

More than sixty configurations were simulated. These simulations combined different tyre profiles, treads, rim designs and spoke orientation on two car types: a sedan and a sports wagon. Two tyre geometries were obtained directly from the tyre manufacturer, while a third geometry was obtained from our database and represents a generic tyre which covers different profiles of a given tyre size. All geometries were deformed based on measured wind tunnel data under a defined load and rotating conditions of $100 \mathrm{kph}$.

Results have shown that the main grooves consistently lead to a decrease of both drag and lift. The edge pattern however, did not show a clear trend for drag and lift with respect to the different configurations studied, although its influence was always more noticeable on the sports wagon. The larger profile of the generic tyre resulted in higher drag and lift values with relation to the tyres obtained from the manufacturer. For a given rim, a drag difference was observed between two tyre geometries with same profile but different tyre tread. These findings lead to the conclusion that tyre profile, as well as tyre pattern, are important to consider. These results were confirmed by wind tunnel tests. In conclusion, the work of aerodynamic optimization of rims cannot be separated from the tyre itself.

\section{INTRODUCTION}

For the past years, sustainability and energy efficiency have become a major area of research and development for the automotive industry. With stricter regulations and tax rates being introduced every year on $\mathrm{CO}_{2}$ emissions and fuel consumption, car manufacturers are pushed into seeking solutions that fulfil legislation requirements and at the same time do not compromise the vehicle performance.

Aerodynamics is one of the several fields where such solutions are pursued.

The forces defining the driving resistance of a ground vehicle are summarised in equation (1):

$$
F_{\text {drive }}=F_{\text {drag }}+F_{\text {acceleration }}+F_{\text {rolling resistance }}+F_{\text {gradient }}
$$

Minimizing the forces in equation (1) is necessary in order to reduce fuel consumption, and aerodynamic drag plays an important role.

Wheels and wheelhouses are shown to contribute to about $25 \%$ of the total aerodynamic drag of a vehicle [1]. The wheel rotation creates a wake which interacts with the car exterior as well as with the under body, influencing the drag contribution of both. The effects of wheel rotation and rim design on passenger cars have been the topic of several studies for the past years. References [1-8] are examples of such studies. However, a limited number of publications into the effects of tyre profile and tyre tread are available in the literature. Some contributions to this topic can be seen in the works of Mercker et al. [9], Landström et al. [10], and Sebben and Landström [11].

This paper focuses mainly on the effects of tyre geometry (tyre profile and tyre tread) on the aerodynamic forces of a vehicle. Both numerical computations and wind tunnel tests were conducted, and the results will be compared to each other whenever possible. However, many of the tyre pattern combinations carried out in the CFD study were not possible to physically reproduce in the tunnel. The study combined 
different configurations involving tyre profile, tyre pattern, rim design, spoke orientation (CFD only) and body type (sedan and sports wagon). The aim was to understand the drag contribution of different tyre features and decide which details are needed to take into consideration when performing CFD analysis. All numerical and experimental results reported in this paper are for moving ground and rotating wheel conditions.

\section{METHODOLOGY}

Both numerical simulations and wind tunnel tests were conducted in this work. Only a brief description of the procedures used will be given in this paper.

\section{Numerical Setup}

The numerical work followed to a large extent the numerical procedure described by Chronéer et al. [13]. The size of the computational domain is $50 \mathrm{~m} \times 10 \mathrm{~m} \times 10 \mathrm{~m}$ (length $\mathrm{x}$ width $\mathrm{x}$ height). The vehicle is placed in the virtual tunnel so that its front end is positioned at about one third of the tunnel length. Upstream and downstream distances are considered to be large enough to minimize the influence of the computational walls.

Meshing was performed using Harpoon v4.4 with final mesh sizes in the range of 110 to 120 million cells depending on level of detail on the tyres. When necessary, a resolution of $1.25 \mathrm{~mm}$ was used on the surface to accurately resolve the tyre pattern. In general, surface resolution over the whole model ranged from 1.25 to $5 \mathrm{~mm}$. This ensured sufficient near wall resolution in order to achieve y+ values below 300 in most regions of the car. Several refinement regions with maximum cell length ranging from 1.25 to $40 \mathrm{~mm}$ were used in the fluid around the vehicle in order to obtain good resolution in important areas. Figure 1 shows two examples of mesh resolutions near the wheels and in the base of the vehicle.

ANSYS Fluent v13x was used as solver. The Realizable k- $\varepsilon$ turbulence model was used together with second order upwind discretization for the momentum equations, and a coupled pressure-velocity solver. A uniform velocity inlet profile of $100 \mathrm{kph}$, turbulence intensity of 0.1 percent, and viscosity ratio of 200 was used in all simulations. The side walls of the numerical wind tunnel were set to symmetry boundary condition and a pressure-outlet condition was prescribed on the outlet surface. The solution was considered to be converged when the residuals of all dependent variables had decreased at least 3 orders of magnitude and drag coefficients had stabilized for the last 1000 iterations. Each simulation ran for 3000 iterations, with drag coefficients oscillating within \pm 0.001 .

All simulations presented in this study were performed using steady state RANS. Wheel rotation was modelled using Multiple Reference Frames (MRF) according to the recommendations given in [14]. Although a limitation, the use

Page 2 of 10 of MRF is a common practice in CFD since it reduces and simplifies the computational effort. A more realistic approach for the representation of the wheel rotation is the use of sliding meshes. However, this was not an option for the authors due to the large number of configurations investigated. In addition, some preliminary studies using MRF on the effect on drag and lift of different tyres had shown reasonable agreement with experiments.

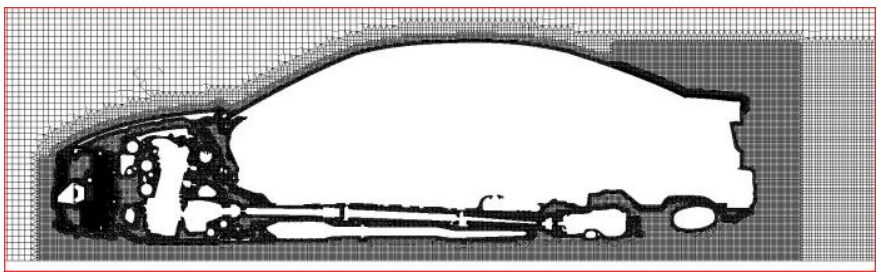

(a)

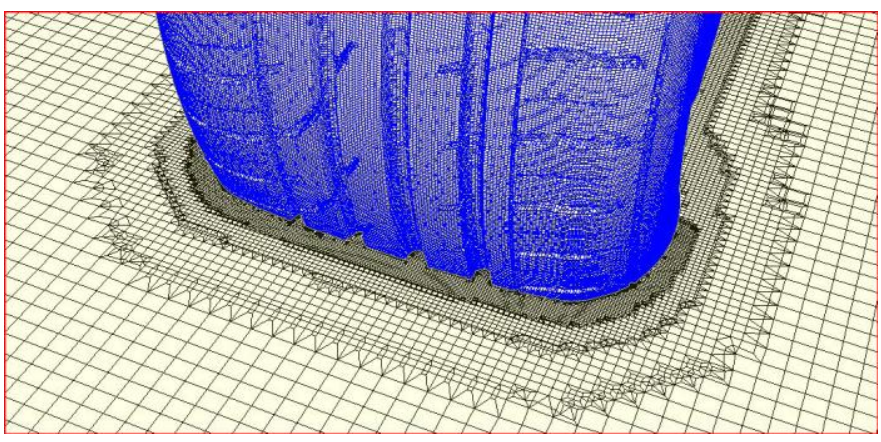

(b)

Figure 1. (a) A clip of the mesh at $y=0$, and (b) The surface mesh of the tyre and the mesh expansion into the fluid.

\section{Experimental Setup}

Wind tunnel experiments were carried out in the Volvo Car Aerodynamic Wind Tunnel. The wind tunnel is of Göttingen type with a slotted wall test section. A 5-belt moving ground system along with boundary layer scoop, suction and tangential blowing are installed in the test section. A detailed description of the wind tunnel can be found in the presentation by Sternéus et al. [12].

Figure 2 show the test car installed in the wind tunnel along with two examples of rim configurations that were investigated. The test car was supported on struts keeping the car at a fixed ride height throughout the test. All aerodynamic forces are measured by a six component balance located below the turn table. The uncertainty level between two configurations during the same test occasion has been statistically established to $\Delta \mathrm{C}_{\mathrm{D}} \leq 0.001, \Delta \mathrm{C}_{\mathrm{LF}} \leq 0.001$, and $\Delta \mathrm{C}_{\mathrm{LR}} \leq 0.005$.

Unfortunately the test object in the wind tunnel and numerical model used in the computations are not exactly the same. The main difference between them is in the different powertrains. It was not possible at the time of this investigation to find a 
test object which matched the available CFD model. However, since the focus of this investigation is the effect on delta $\mathrm{Cd}$ of different tyre geometry properties, it is believed and assumed that powertrain differences do not affect our conclusions.

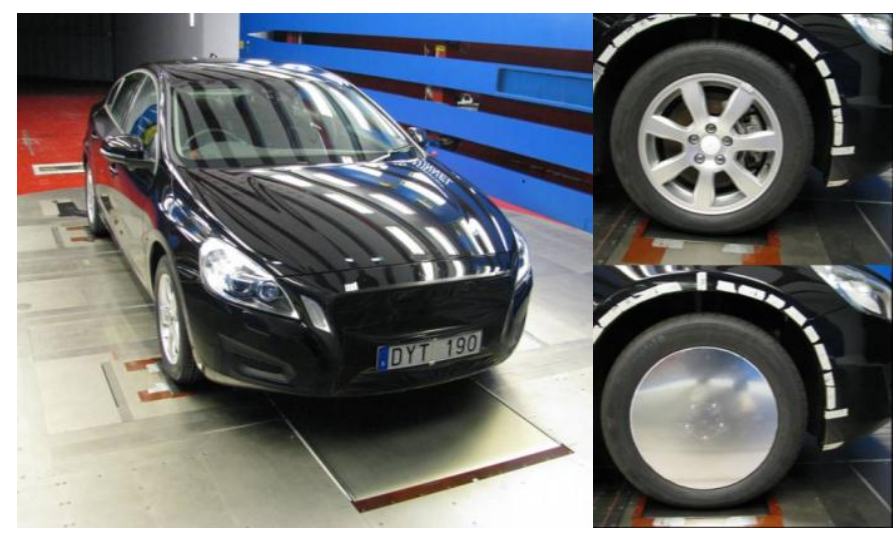

Figure 2. Test object in the wind tunnel (left) and two of the rims investigated (right): Oden (top), and Flat (bottom).

\section{CONFIGURATIONS}

Two vehicle types were considered in the numerical work: the Volvo S60 and the Volvo V60. Experimental results, however, were only performed in the S60, due to time constrains.

More than sixty configurations were simulated in CFD. These simulations combined different tyre deformation techniques, different tyre profiles and pattern, in addition to rim designs and spoke orientation. Two tyre geometries were obtained directly from the tyre manufacturer, while a third geometry was obtained from our database and represents a generic tyre which covers different profiles of a given tyre size. An overview of these configurations is presented in this section.

\section{Tyre Deformation}

The tyre deformation under the weight of the car and due to the rotation of the wheels needs to be replicated in the numerical model. Previous work by Sebben and Mlinaric [14], and Landström et al. [10] have described and measured the deformations of the tyre due to centrifugal forces from wheel rotation. The applied deformation also preserved the contact patch measured on a real tyre at stationary position. It is not possible for the authors to measure changes in contact patch area due to wheel rotation during the course of wind tunnel tests. The main difference between the two types of deformations investigated was the preservation, or not, of the tyre main grooves at the ground plane.

Figure 3 shows the contact patch area when deformations 1 and 2 are applied. Preserving the main grooves as in Figure 3 (b) is a more realistic deformation of the tyre.

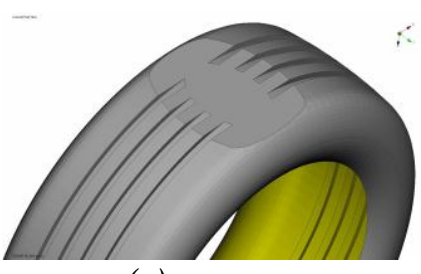

(a)

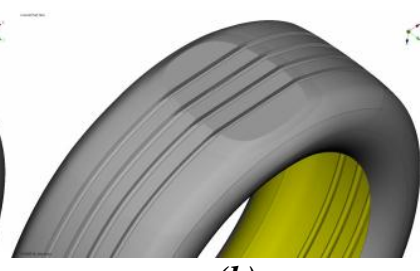

(b)
Figure 3. View of the tyre main grooves at contact patch: (a) Deformation 1, grooves are interrupted at ground, and (b) Deformation 2, grooves are connected at ground.

\section{Tyre Profile}

The tyre profile referred to in this paper is the inflated section drawing of the tyre (see Figure 4). The two CAD tyres obtained from the manufactures are hereafter referred to as Tyre 1 (T1) and Tyre 2 (T2), while the tyre obtained from our database is referred to as Generic Tyre $(\mathrm{G})$, and it is more "balloon" shaped. Figure 4 shows the difference between the $\mathrm{T} 1$ and $\mathrm{G}$ profiles investigated. Tyre 1 and 2 have very similar profiles except for a very small side groove.

Note that the main grooves were manually created in the Generic Tyre and have a more "rectangular" shape. Most of the results reported in this paper involve Tyre 1.

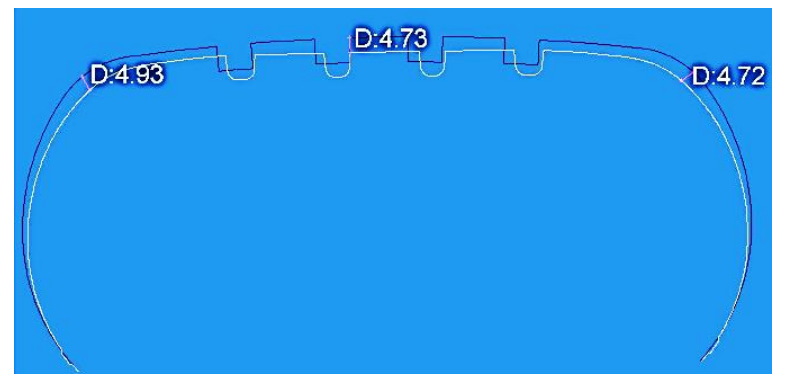

Figure 4. Tyre profiles investigated: Generic Tyre (dark blue contour) and Tyre 1 (white contour). Distances in $\mathrm{mm}$.

\section{Tyre Pattern}

Three main pattern features were identified for this study, namely: main grooves, side grooves and edge pattern. A total of eight combinations were evaluated with these features for T1. The pattern features are shown in Figure 5, each separately on a slick tyre. The features investigated are highlight with a darker colour.

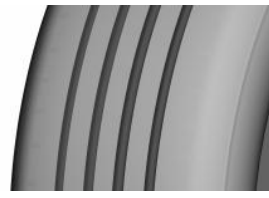

(a)

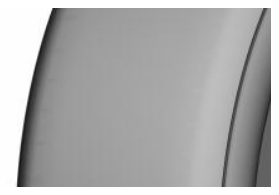

(b)

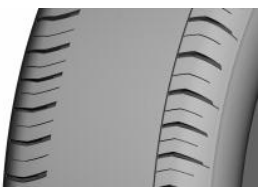

(c)
Figure 5. Tyre pattern features investigated: (a) main grooves, (b) side grooves, and (c) edge pattern. 


\section{Rim Design and Spoke Orientation}

Two rim designs were used for this study with a variation on each thus leading to four rim designs in total. The Creon rim shown in Figure 6(a) has been rotated by 36 degrees (Figure 6(b)) from its original position in order to invert the spoke's position. A similar investigation has been conducted by Landström [7] which showed a dependency of the flow on spoke position especially for thick spokes, when computing in steady state and without a rotating mesh. The Oden rim presented in Figure 6(c) has been closed by a flat plate on the outer most section of the rim (Figure 6(d)) in order to simulate a closed rim. The Oden rim was also rotated in order to invert the spoke's position. However, since the numerical results showed practically no difference, the results of this configuration will be omitted in this paper.

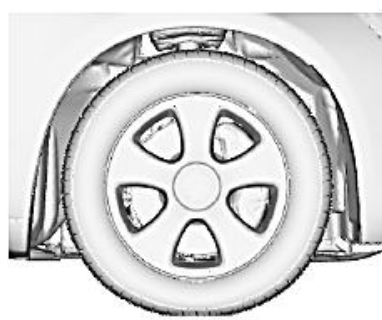

(a)

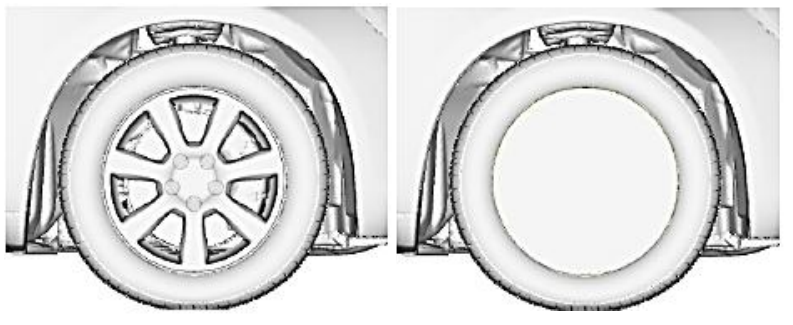

(c)

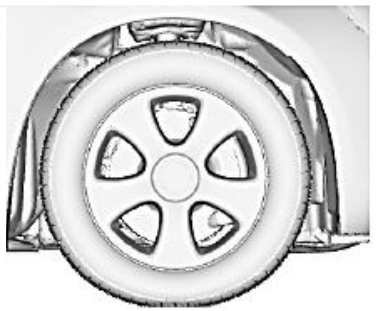

(b)

(d)
Figure 6. Rim configurations: (a) Creon, (b) Creon rotated, (c) Oden, and (d) Flat.

\section{Vehicle Type}

The cars investigated share the same platform and wheelbase. This means that they differ from each other only by the top hat. A front-side view of the models is seen in Figure 7.

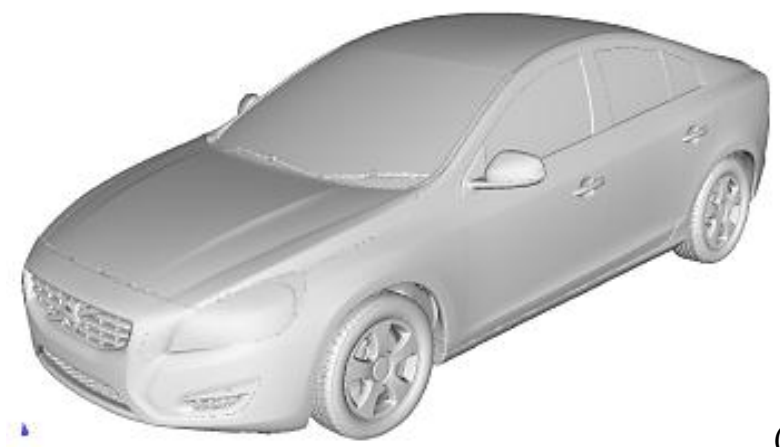

(a)

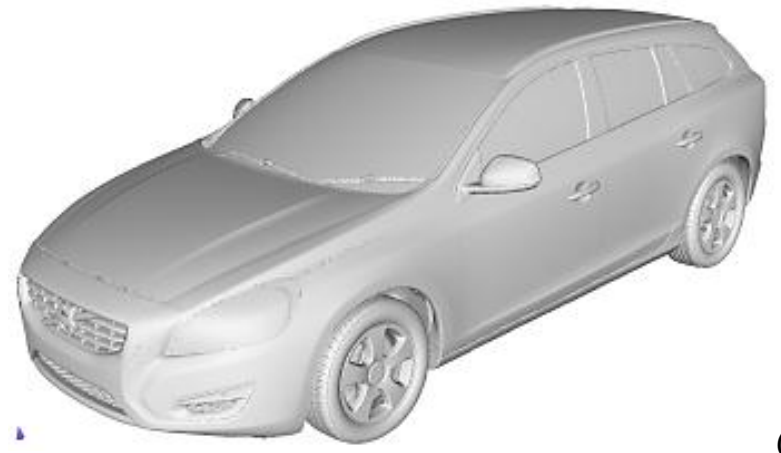

(b)

Figure 7. Vehicle type: (a) Volvo S60 and (b) Volvo V60.

\section{$\underline{\text { RESULTS }}$}

This section presents the results divided accordingly to the different issues investigated. A comparison of the numerical and experimental results will be performed whenever possible.

\section{Tyre Deformation}

The different sets of deformations were applied both on the slick tyres as well as on the tyres with main grooves (rain grooves). The largest difference is observed with the grooved tyre. Results for the Generic Tyre and the rim type Creon are summarized in Table 1.

Table 1. Deformation 1 versus Deformation 2. Values are count differences to reference: Def.1 Slick. The $\Delta$ row is the difference between grooved and slick.

\begin{tabular}{|c|c|c|c|c|}
\hline \multirow{2}{*}{ Tyre Config. } & \multicolumn{2}{|c|}{ Drag } & \multicolumn{2}{c|}{ Lift } \\
\cline { 2 - 5 } & Def. 1 & Def. 2 & Def. 1 & Def. 2 \\
\hline Slick & 0 & 3 & 0 & 10 \\
\hline Grooved & 6 & -1 & 9 & -14 \\
\hline$\Delta$ & 6 & -4 & 9 & -24 \\
\hline
\end{tabular}

Figure 8 shows the difference on drag distribution on the tyre when having the main grooves interrupted (Def. 1) or connected (Def. 2) at the contact patch, as Figure 8(a) and 8(b) show, respectively. Note that the figure only shows the effect on the tyre itself although the flow field around it also changed, affecting the car pressure distribution as well. An increase in base pressure could be seen without much effect on the rear wake structure. The grooves seem to diminish the jetting effect on the rear wheels by allowing air through.

All the following up results in this paper are with respect to Def. 2.

Page 4 of 10 


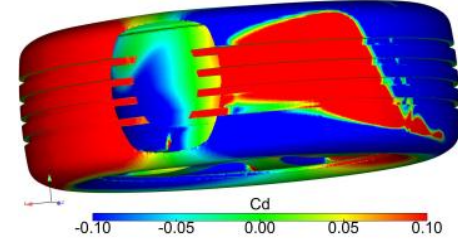

(a)

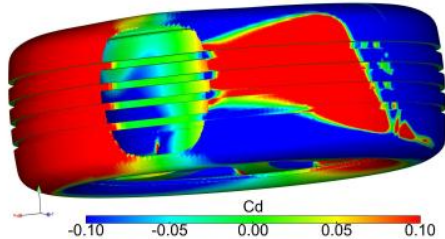

(b)
Figure 8. Comparison of drag distribution on a Generic Tyre using: (a) Def. 1 and (b) Def. 2.

\section{Tyre Profile}

Only the profiles of the Generic Tyre (G) and Tyre 1 (T1) are compared, since profiles of $\mathrm{T} 1$ and $\mathrm{T} 2$ were practically identical. Simulations were performed for both slick and main grooved tyres, using Def. 2, and for two types of rims: Creon and Oden. Results are summarized in Table 2.

Table 2. Influence in drag and lift due to tyre profile, $G$ and $T 1$, for two rim types. Values reported are deltas between main grooved minus slick tyres.

\begin{tabular}{|c|c|c|c|c|}
\hline \multirow{2}{*}{ Rim Config. } & \multicolumn{2}{|c|}{ Drag } & \multicolumn{2}{c|}{ Lift } \\
\cline { 2 - 5 } & Generic & $\mathrm{T} 1$ & Generic & $\mathrm{T} 1$ \\
\hline Creon & -4 & -1 & -24 & -12 \\
\hline Oden & -3 & -3 & -19 & -15 \\
\hline
\end{tabular}

Adding the main grooves to a slick tyre gives a consistent trend of slight drag reduction, between -1 to -4 counts, and a lift reduction between -12 to -24 counts. The reduction in drag and lift are of the same order of magnitude for both rims. However, looking at the profile differences, the Generic Tyre shows a larger reduction in both drag and lift. This can be explained by the fact that the Generic Tyre is slightly wider and with a sharper edge, as shown in Figure 4.

Drag and lift differences between the slick Generic Tyre and the slick production tyre $\mathrm{T} 1$ is given in Table 3 for two types of rims, using Def. 2. The slender profile of Tyre 1 leads to lower $\mathrm{Cd}$ and $\mathrm{Cl}$ vaues, as it was expected.

Table 3. Values are count differences between slick Tyre 1 and slick Generic Tyre.

\begin{tabular}{|c|c|c|}
\hline \multirow{2}{*}{ Rim Config. } & \multicolumn{2}{|c|}{ Tyre $1-$ Generic Tyre } \\
\cline { 2 - 3 } & Drag & Lift \\
\hline Creon & -2 & -17 \\
\hline Oden & -2 & -15 \\
\hline
\end{tabular}

\section{Tyre Pattern Features}

Three main pattern features were identified in Tyre 1 and are investigated in this study, namely: main grooves, side grooves and edge pattern. All three features were simulated on 4 rims with 8 different combinations, thus yielding a total of 32 simulations. The main results are presented in this section.

\section{Main Grooves}

Figure 9 summarizes the results of adding the main grooves on different tyre pattern configurations, namely, flat, with side groove, with edge pattern, and with both side groove and edge pattern. As shown in the figure, adding the main grooves results in a decrease in drag and lift due to the fact that the grooves connect the high pressure region in front of the tyre to the low pressure region behind the tyre, according to Def. 2 .

This diminishes the jetting effect around the tyre and creates a low pressure region inside the grooves as the flow accelerates through. Similar observations have been made in $[15,16]$. The drag decrease was around -2 and -3 counts, while lift decrease was mostly between -10 and -15 counts.

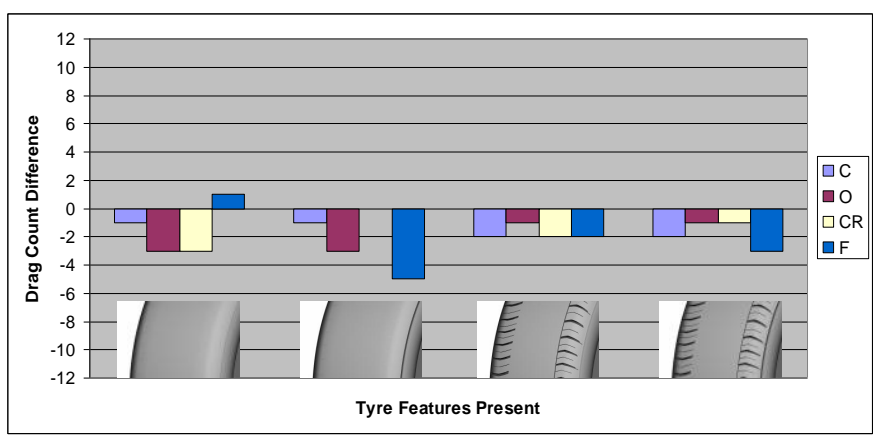

(a)

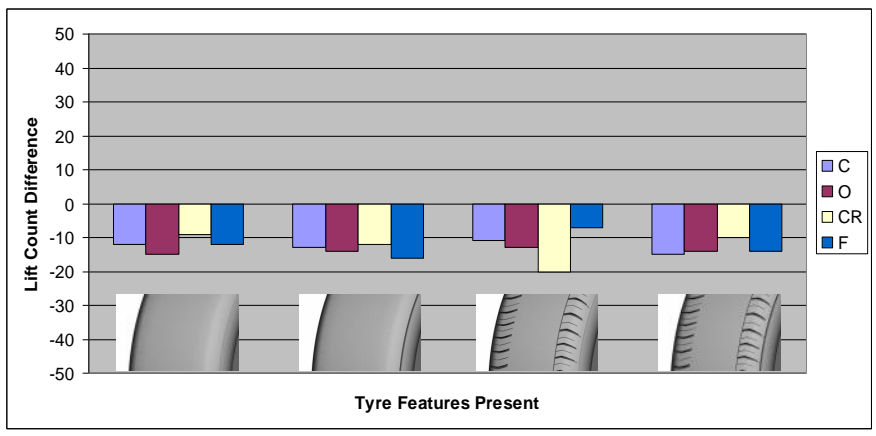

(b)

Figure 9. Changes in aerodynamic forces: (a) Drag, and (b) Lift, when main grooves are added on different tyre pattern configurations. Four rims: Creon $(C)$, Oden, $(O)$, Creon rotated $(C R)$, and closed rim $(F)$. 


\section{Side Grooves}

Similarly, Figure 10 summarizes the results of adding side grooves on different tyre pattern configurations. Adding the side grooves led to an increase in drag in all simulations with open rims. The variations in lift can be related to the separation of the flow due to the side groove however no clear trend can be seen.

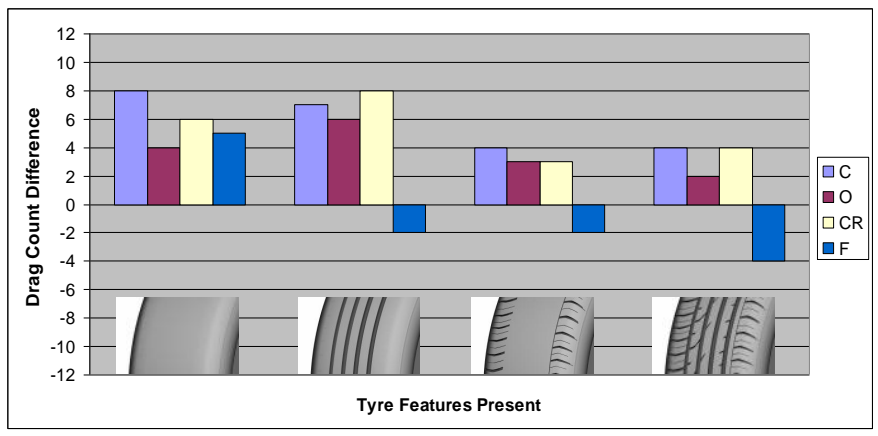

(a)

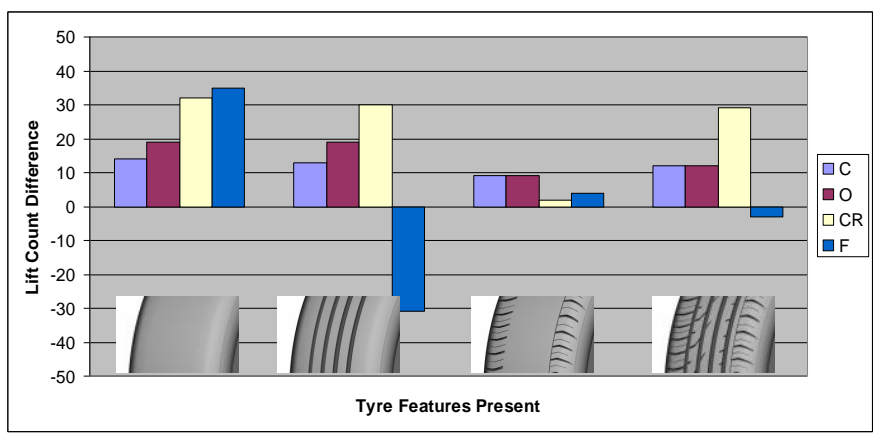

(b)

Figure 10. Changes in aerodynamic forces: (a) Drag, and (b) Lift, when side grooves are added on different tyre pattern configurations. Four rims: Creon (C), Oden, $(O)$, Creon rotated $(C R)$, and closed rim $(F)$.

The biggest difference that the side grooves introduced was a clear separation of the flow on the front wheel, as shown in Figure 11. This separation resulted in a total drag increase for the vehicle, mostly due to an increase of the front wheel drag.

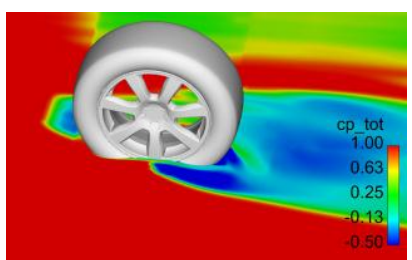

(a)

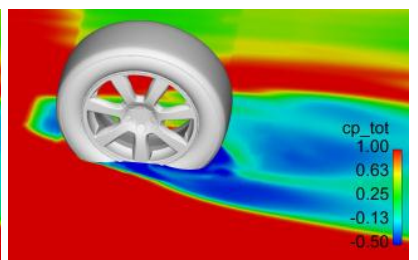

(b)
Figure 11. Plots of total Cp distribution on: (a) Slick tyre and (b) Slick tyre with side groove.

\section{Edge Pattern}

No clear trend on the aerodynamic forces could be observed by adding the edge pattern to the various tyre configurations, as Figure 12 shows. However, a consistent drop in rear base pressure was observed as shown in Figure 13.

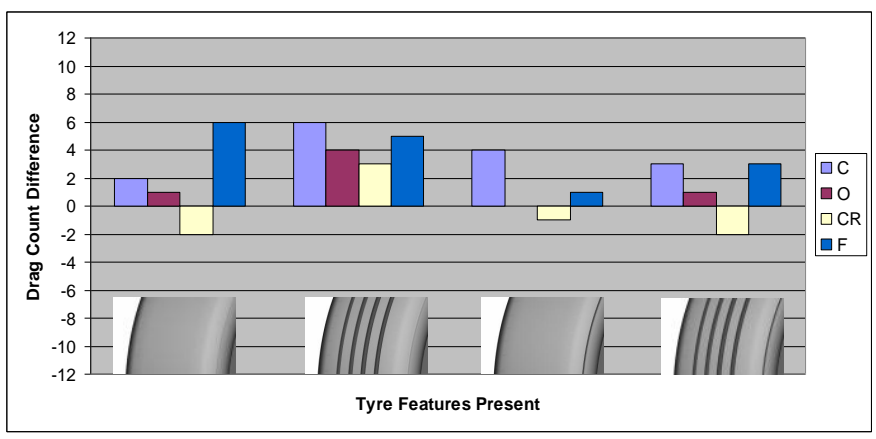

(a)

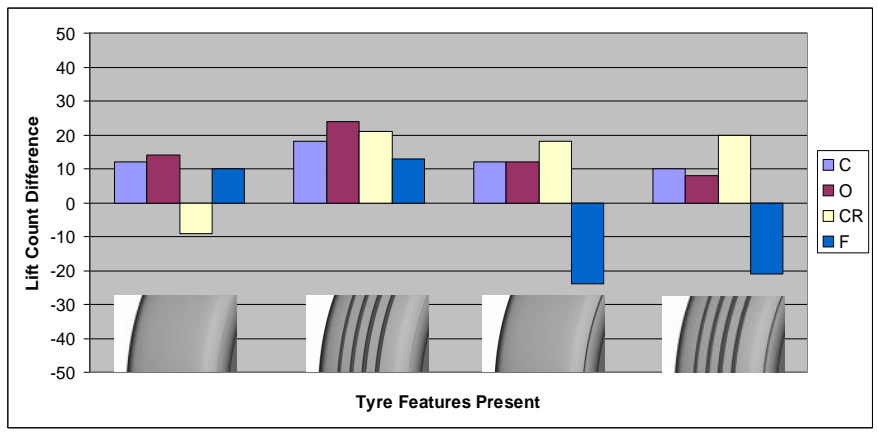

(b)

Figure 12. Changes in aerodynamic forces: (a) Drag, and (b) Lift, when edge pattern is added on different tyre pattern configurations. Four rims: Creon (C), Oden, $(\mathrm{O})$, Creon rotated $(C R)$, and closed rim $(F)$.

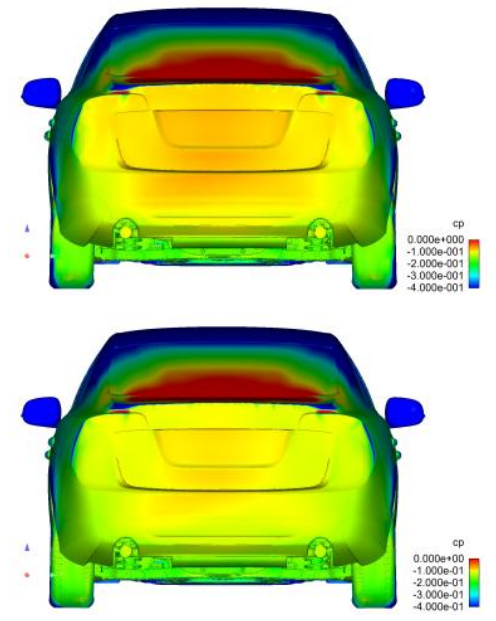

Figure 13. Distribution of the pressure at the base: (a) Slick, and (b) Slick plus edge pattern. 


\section{Edge Pattern and Side Groove}

The effect of adding two features at a time can also be studied from the configurations. The absence of a trend for adding the edge pattern has been explained by the existence of a unique interaction with the side grooves. This interaction can be seen as a consistent drag and lift increase when both features are added together. The magnitude of the increase is shown to be dependent on the rim being used. The results are summarized in Figure 14.

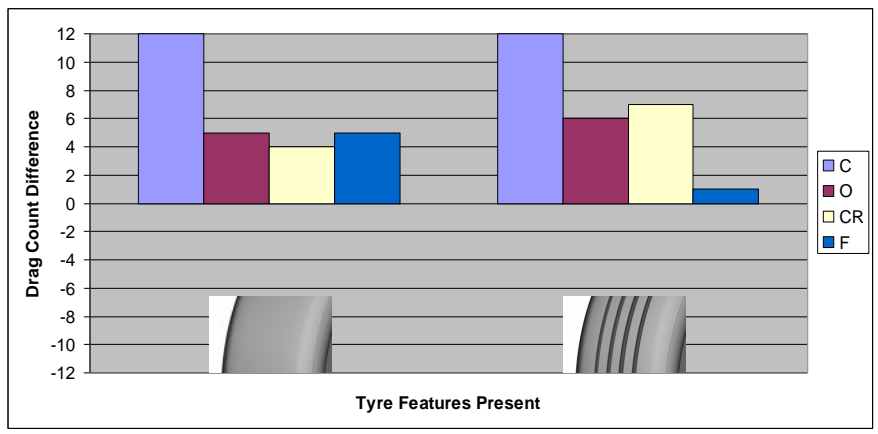

(a)

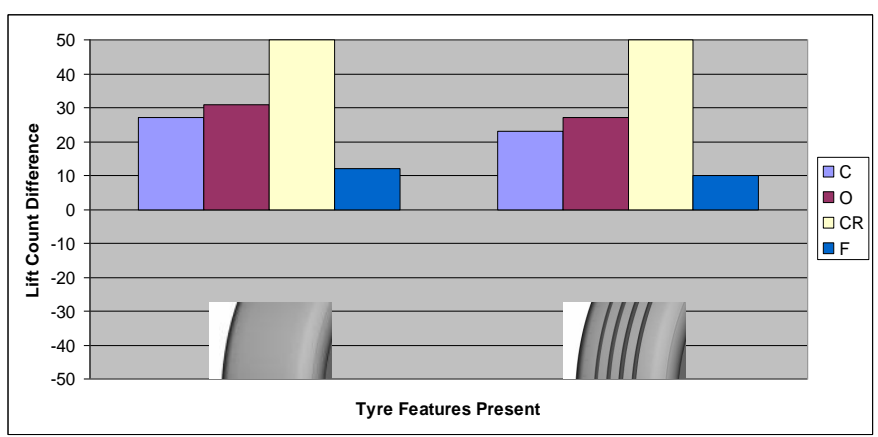

(b)

Figure 14. Changes in aerodynamic forces: (a) Drag, and (b) Lift, when edge pattern plus side groove are added on different tyre pattern configurations. Four rims: Creon $(C)$, Oden, $(O)$, Creon rotated $(C R)$, and closed rim $(F)$.

\section{$\underline{\text { Full Pattern }}$}

The results of adding the full pattern on a slick tyre are reported in Figure 15. Adding the full pattern showed an increase in drag in all cases with the magnitude of the increase being dependent on the rim configuration. The drag differences between slick and pattern tyres were quite visible in the flow field. The contribution from the front wheels can be seen when plotting local drag and vorticity around $\mathrm{x}$-axis. The contribution from the rear wheels is more obvious in the rear wake and base pressure.

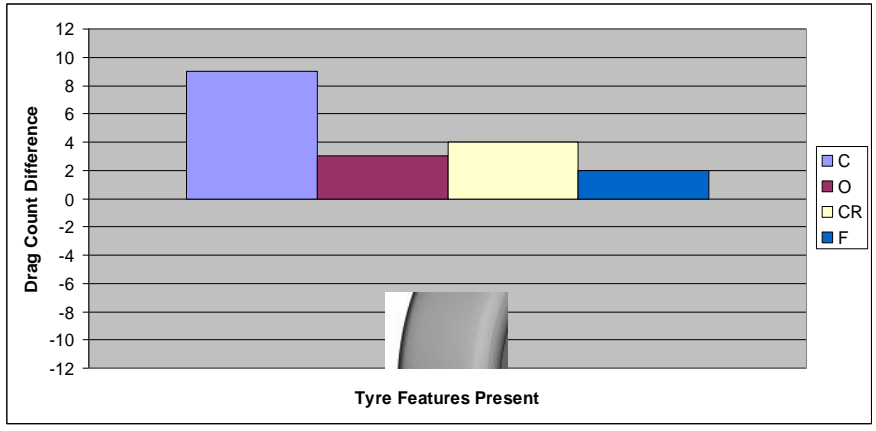

(a)

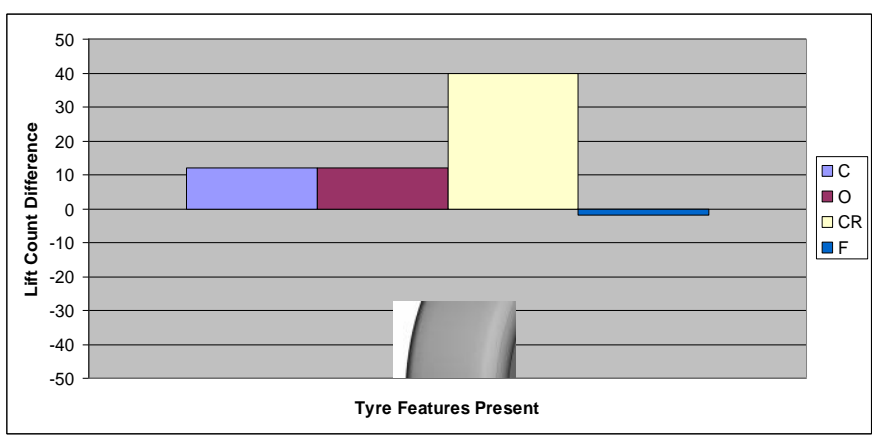

(b)

Figure 15. Changes in aerodynamic forces: (a) Drag, and (b) Lift, when full pattern is added on different tyre pattern configurations. Four rims: Creon (C), Oden, (O), Creon rotated $(C R)$, and closed rim $(F)$.

In previous work by Sebben and Landström [11], wake measurements in the wind tunnel were performed in a plane $500 \mathrm{~mm}$ behind the front wheel. The test setup included an Oden rim with a T1 tyre on the sedan vehicle. Figure 16 shows that a full tyre pattern improves the flow field prediction compared to the slick tyre.

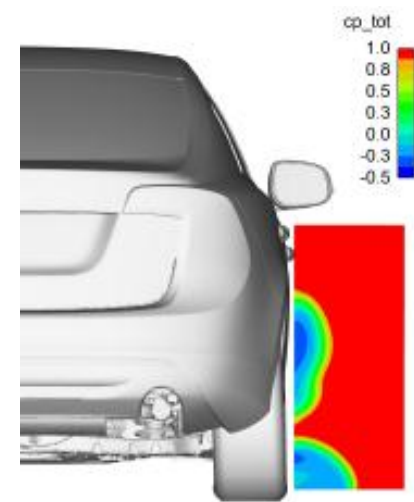

(a)

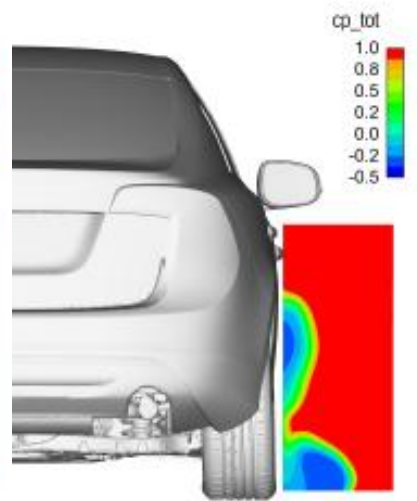

(b) 


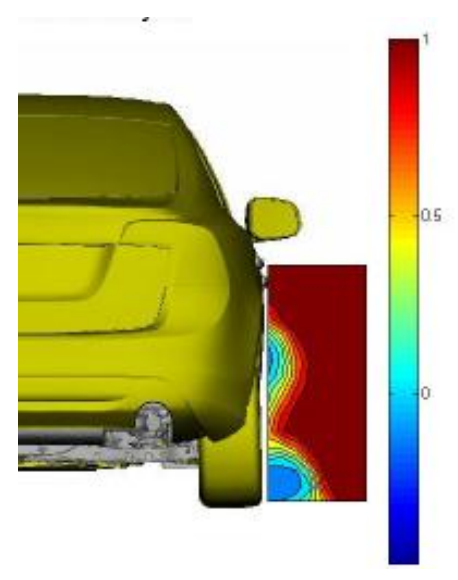

(c)

Figure 16. Comparison of flow structures 500mm behind the front wheel: (a) slick tyre, CFD, (b) full pattern tyre, $C F D$, and (c) experimental results.

Notice that with the full pattern the two wakes are connected as in the tunnel measurements, this is attributed to the edge pattern and side groove presence. Two separated wakes are obtained with the slick tyre.

Differences could also be seen between the left and right tyre flow structures. This was a result of the tyre pattern not being directional but rather asymmetric. Thus the patterns on the right and left side are oriented differently causing different flow behaviour. Both show considerable increase in local drag compared to the flow around a slick tyre, mainly due to the strong vortices they induce into the flow. Figure 17 shows the differences in local drag with a picture of the tyre tread orientation above each respective case.
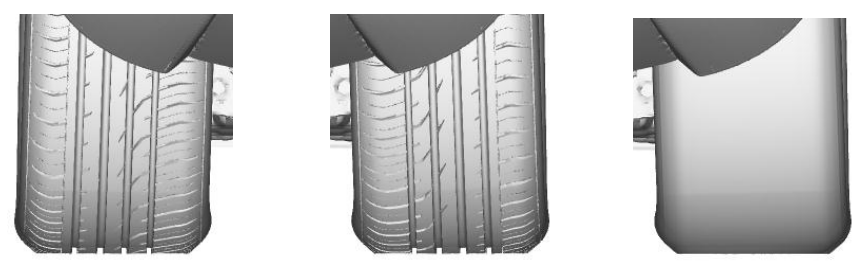

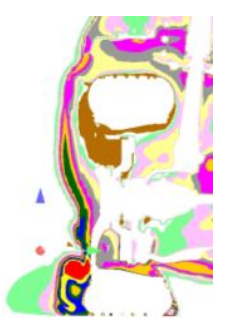

(a)

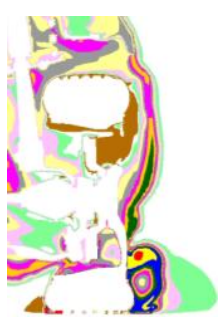

(b)

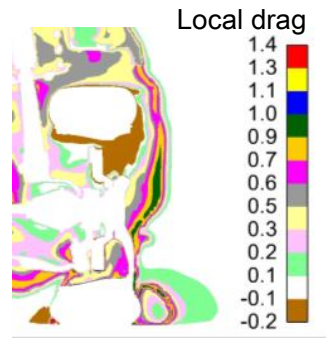

(c)
Figure 17. Changes in local drag in a plane normal to the $x$ axis at front wheel centre: (a) left tyre with full pattern, (b) right tyre with full pattern, and (c) right tyre slick.

\section{Sedan versus Sports Wagon}

Figure 18 presents the results when tyre features are added one at a time on the sedan and the sports wagon. All cases are for Tyre 1 and rim type Creon. The drag and lift increase when the edge pattern is added on the tyre is significantly larger on the sports wagon than on the sedan.

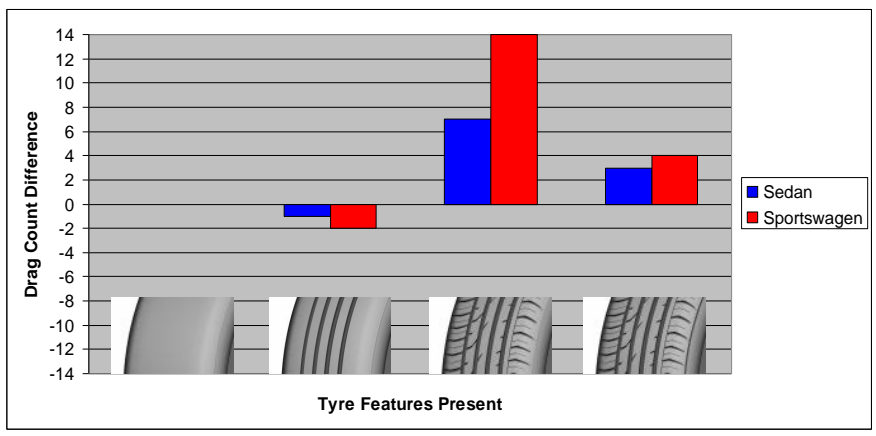

(a)

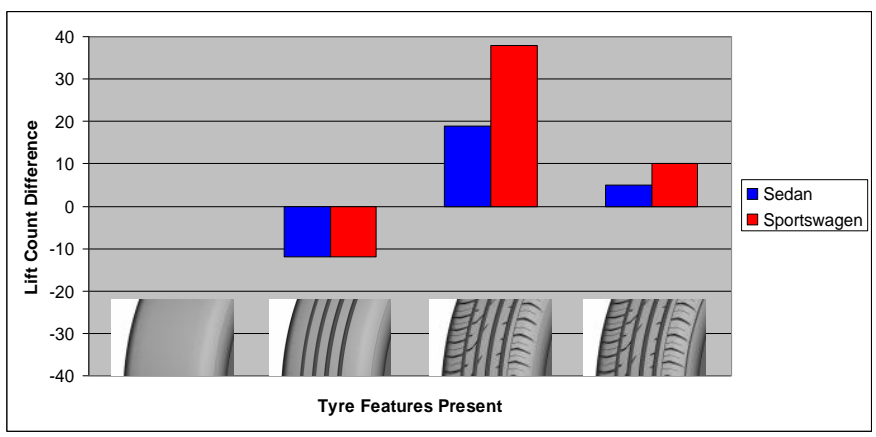

(b)

Figure 18. Change in forces when the pattern features are added one at a time. The plotted values are deltas to the previous configuration going from left to right.

\section{Tyre 1 versus Tyre 2}

Tyre 2 showed a consistent reduction in drag for all configurations with the magnitude of that reduction being rim and spoke position dependent. Due to its significantly thinner spokes, the Oden rim is expected to have less spoke position dependency than the Creon rim, but no simulations were done on a rotated Oden rim. The results of the simulations are summarized in Table 4.

Table 4. Results of Tyre 1 and Tyre 2 comparison in simulations. All values are count differences between Tyre 2 and Tyre 1.

\begin{tabular}{|c|c|c|c|}
\hline \multirow{2}{*}{$\begin{array}{c}\text { Tyre } \\
\text { Comparison } \\
\text { vs. Rim }\end{array}$} & \multicolumn{3}{|c|}{ Tyre 2-Tyre 1 } \\
\cline { 2 - 4 } & $\mathrm{Cd}$ & $\mathrm{Clf}$ & $\mathrm{Clr}$ \\
\hline
\end{tabular}




\begin{tabular}{|c|c|c|c|}
\hline Oden & -4 & -2 & 2 \\
\hline Creon & -1 & -4 & 8 \\
\hline Creon Rotated & -11 & -20 & -12 \\
\hline
\end{tabular}

As both tyres have almost identical profiles and main grooves, the reduction in drag can be related to the absence of the side groove on the T2 tyre and the smoother edge pattern. This conforms to the results mentioned previously on the effect of these features. Results of the local drag changes are shown in Figure 19 with a picture of the tyre tread above each respective case. Note also the similarity between Figures 19(b) and 19(c). This shows that similar flow fields can be obtained from slick and full pattern tyre. This comes as a combination of having a smooth tyre tread to side wall transition. In this case the main grooves and edge pattern seem to suppress one another's effects, thus resulting in little drag increase.
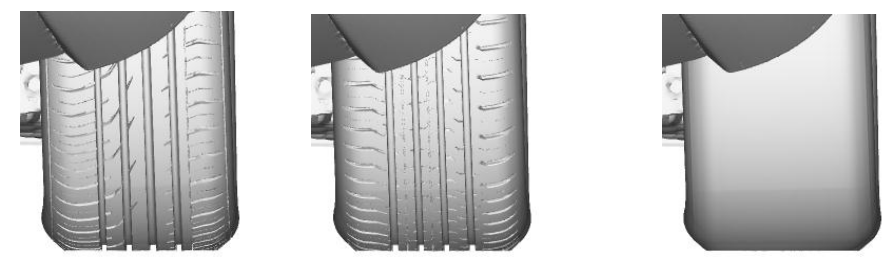

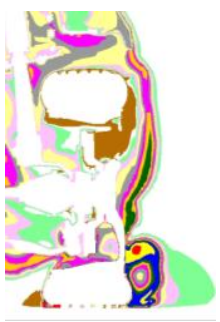

(a)

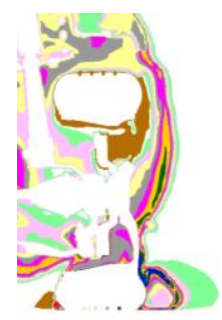

(b)

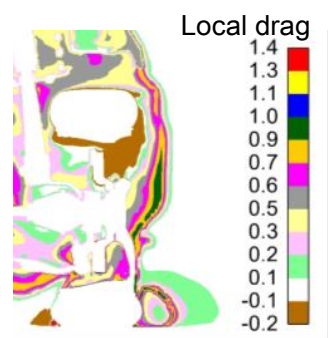

(c)
Figure 19. Change in local drag in a plane normal to the $x$ axis at front wheel centre for: (a) Tyre 1, (b) Tyre 2, and (c) slick tyre.

Tyres 1 and 2 have been compared in both tests and simulations on the Oden rim. The simulations and tests showed similar results which are summarized in Table 5 .

Table 5. Results of Tyre 1 and Tyre 2 comparison from both tests and CFD simulations. All values are count differences between Tyre 2 and Tyre 1.

\begin{tabular}{|c|c|c|c|}
\hline \multirow{2}{*}{} & \multicolumn{3}{|c|}{ Tyre 2-Tyre 1 } \\
\cline { 2 - 4 } & $\mathrm{Cd}$ & Clf & Clr \\
\hline Numerical & -4 & -2 & 2 \\
\hline Experimental & -5 & 3 & 2 \\
\hline
\end{tabular}

Page 9 of 10

\section{CREON versus ODEN}

An experimental investigation has also been performed on comparing the Oden and Creon rims with two different sets of tyres. Due to availability reasons Tyre 2 has been replaced by another tyre, Tyre 3. The results have shown a strong interaction between the rim and tyre. Different tyres resulted in different rim aerodynamic performance. These results are summarized in Table 6.

Table 6. Results of Creon and Oden comparison with Tyre 1 and Tyre 3. All values are count differences between Oden and Creon.

\begin{tabular}{|c|c|}
\hline & Oden - Creon \\
\cline { 2 - 2 } & Cd \\
\hline Tyre 1 & -1 \\
\hline Tyre 3 & -4 \\
\hline
\end{tabular}

\section{CONCLUSIONS}

- Tyre deformations made according to deformation 2 have been shown to preserve tyre features at contact patch. This deformation is recommended since it is more realistic.

- Tyre profiles have shown differences in aerodynamic forces thus a real tyre profile is recommended for CFD applications.

- The tyre pattern features investigated have shown different effects on drag and lift. Adding main grooves have shown a trend of constant reduction in drag and lift. Adding the side grooves and edge pattern separately did not show a clear trend which is explained by the existence of a strong interaction between the two. This is clear from the trend of drag and lift increase when both are added together.

- Magnitudes of drag and lift changes due to tyre features have shown to be rim dependent, including spoke position dependency.

- The tyre pattern, specifically the edge pattern, has shown a bigger impact on a sports wagon than on a sedan. As the edge pattern has shown direct impact on the base pressure of the vehicle the resultant change in drag increased for a larger base.

- Tyre 2 has shown to result in lower drag than Tyre 1 in both CFD simulations and wind tunnel tests. The drop in drag has shown to be consistent in both.

- Tyres with smooth edge pattern to side wall transition have shown the possibility to generate similar flow fields to slick tyres with identical profiles.

- As a strong interaction is shown between rim designs and tyre patterns, it is recommended to use sliding mesh 
simulations with fully detailed tyre pattern when investigating rim designs in CFD. It is also recommended to use identical tyres when comparing rims in wind tunnel tests.

\section{REFERENCES}

1. Wickern G., Zwickern K., and Pfadenhauer M., "Rotating Wheels - Their Impact on Wind Tunnel Test Techniques and on Vehicle Drag Results", SAE Technical Paper 1997- 970133.

2. Pfadenhauer M., Wickern G., and Zwicker, K., "On the Influence of Wheels and Tyres on the Aerodynamic Drag of Vehicles", MIRA International Conference on Vehicle Aerodynamics, October 1996.

3. Elofsson, P. and Bannister, M., "Drag Reduction Mechanisms Due to Moving Ground and Wheel Rotation in Passenger Cars", SAE Technical Paper 2002-01-0531.

4. Modlinger, F. and Adams N., "New Directions in the Optimization of the Flow around Wheels and Wheels Arches", 7th MIRA International Conference on Vehicle Aerodynamics, October 2008.

5. Modlinger, F. and Adams, N., "New Directions in the Optimization of the Flow around Wheels and Wheels Arches", 7th MIRA International Conference on Vehicle Aerodynamics, October 2008.

6. Landström C., Walker T., and Löfdahl L., "Detailed flow studies in close proximity of rotating wheels on a passenger car", SAE Technical Paper 2009-01-0778.

7. Landström, C., Sebben, S. and Löfdahl, L., "Effects of Wheel Orientation on Predicted Flow Field and Forces When Modelling Rotating Wheels Using CFD”, $8^{\text {th }}$ MIRA International Conference on Vehicle Aerodynamics, October 2010.

8. Landström, C., Josefsson, L., Walker, T., and Löfdahl L., "An experimental investigation of wheel design parameters with respect to aerodynamic drag", $8^{\text {th }}$ FKFS Conference - Progress in Vehicle Aerodynamics and Thermal Management, 2011.

9. Mercker, E., Breuer, N., Berneburg H., and Emmelmann H.J., "On the Aerodynamic Interference Due to the
Rolling Wheels of Passenger Cars", SAE Technical Paper 1991-910311.

10. Landström, C., Josefsson, L., Walker, T., and Löfdahl, L., "Aerodynamic effects of different tyre models on a sedan type passenger car", SAE Technical Paper 2012-01-0169.

11. Sebben, S. and Landström, C., "Prediction of Aerodynamic Drag for Different Rim Designs Using Varied Wheel Modelling in CFD", $8^{\text {th }}$ FKFS Conference - Progress in Vehicle Aerodynamics and Thermal Management, 2011.

12. Sternéus, J., Walker, T., and Bender, T., "Upgrade of Volvo Cars Aerodynamic Wind Tunnel”, SAE Technical Paper 2007-01-1043.

13. Chronéer, Z., Borg, A., and Sebben, S., "The CFD Process for Aerodynamics at Volvo Cars using HARPOON-FLUENT", EACC, Frankfurt, Germany, 2007.

14. Sebben, S. and Mlinaric, P., "Investigation of the Influence of Tyre Deflection and Tyre Contact Patch on CFD Predictions of Aerodynamic Forces on a Passenger Car", 7th MIRA International Vehicle Aerodynamics Conference, October 2008.

15. Dimitriou, I. and Klussmann, S., "Aerodynamic Forces of Exposed and Enclosed RotatingWheels as an Example of the Synergy in the Development of Racing and Passenger Cars", SAE Tecnical Paper 2006-01-0805.

16. Mears, A., Dominy, R., and Sims-Williams, D., "The Air Flow About an Exposed Racing Wheel", SAE Technical Paper 2002-01-3290.

\section{ACKNOWLEDGMENTS}

The authors would like to thank Tim Walker and Mats Beckman at Volvo Cars for their help and valuable comments. The authors are also very grateful to Continental Tyres for their valuable support throughout this work. 